\title{
HEAT TRANSFER BETWEEN AN AUTOMOTIVE EXHAUST AND THERMOELECTRIC MODULES
}

\author{
A. L. C. Silva \\ Centro Federal de Educação Tecnológica de \\ Minas Gerais (CEFET-MG) \\ Departamento de Engenharia Mecatrônica \\ Bairro Bela Vista, CEP 35500-822 \\ Divinópolis, Minas Gerais, Brasil \\ andrelcsilva92@gmail.com
}

Received: April 09, 2018

Revised: May 18, 2018

Accepted: May 31, 2018

\section{ABSTRACT}

This work aimed to study the heat transfer between an exhaust pipe of a car and thermoelectric modules. Heat transfer is the energy transport that occurs when quantities of matter that have different temperatures are placed in thermal contact and can occur in 3 different modes: conduction, convection and radiation. Thermoelectrics can convert thermal energy into electrical energy and vice versa. In this work a decision was made to install the Peltier cells in the final part of the exhaust pipe, where the temperature is lower. The temperature difference was $59^{\circ} \mathrm{C}$. After calculations were found the values of the heat transfer rate: by conduction $0.164 \mathrm{~W}$, by convection 0.103 and radiation 0.459 .

Keywords: heat transfer, thermoelectric, Peltier Seebeck effect

\section{NOMENCLATURE}

\section{A $\quad$ area, $\mathrm{m}^{2}$}

$\mathrm{C}_{1} \quad$ integration cosntant

$\mathrm{C}_{2}$ integration constant

$\mathrm{Eg} \quad$ rate of internal energy generation, W.

$\mathrm{h}_{\mathrm{x}} \quad$ coefficient heat transfer by convection,

$$
\mathrm{W} / \mathrm{m}^{2} . \mathrm{K}
$$

$\overline{\mathrm{h}_{\mathrm{x}}}$ mid convection heat transfer coefficient,

$\mathrm{W} / \mathrm{m}^{2} \cdot \mathrm{K}$

I

K

$\mathrm{k}$

$\mathrm{L}$

$\mathrm{p}$

$\operatorname{Pr}$

$\mathrm{P}_{\mathrm{a}}$

$\dot{\mathrm{q}}$

$\mathrm{R}$

$\operatorname{Re}$

$\mathrm{T}$

$T_{\mathrm{s}}$

$\mathrm{T}_{\infty}$

$\mathrm{T}_{\mathrm{viz}}$

$\mathrm{V}$

electric current, A

thermal conductivity, $\mathrm{W} / \mathrm{m}^{2} . \mathrm{K}$

fluid thermal conductivity, $\mathrm{W} /(\mathrm{m} . \mathrm{K})$

surface length, $\mathrm{m}$

pressure, $\mathrm{N} / \mathrm{m}^{2}$

fluid Prandtl number, $v / \alpha$

precision limit of quantity a

heat transfer rate, $\mathrm{W}$

electrical resistance, $\mathrm{R}$

Reynolds number

average fluid temperature, $\mathrm{K}$

surface temperature, $\mathrm{K}$

ambient temperature, $\mathrm{K}$

vicinity temperature, $\mathrm{K}$

reference speed of the fluid, $\mathrm{m} / \mathrm{s}$

\section{Greek symbols}

$\alpha \quad$ thermal diffusivity, $\mathrm{m}^{2} / \mathrm{s}$

$\alpha \quad$ Seebeck coefficient, $\mathrm{V} / \mathrm{K}$

$\theta \quad$ dimensionless temperature

$v \quad$ fluid kinematic viscosity, $\mathrm{m}^{2} / \mathrm{s}$

$\rho$ density, $\mathrm{kg} / \mathrm{m}^{3}$

$\mathrm{P}$ electrical resistivity, ohm.m

$$
\begin{array}{ll}
\sigma & \text { Stefan-Boltzmann constant, } \mathrm{W} / \mathrm{m}^{2} . \mathrm{K}^{4} \\
\varepsilon & \text { emissivity } 0 \leq \varepsilon \leq 1
\end{array}
$$

\section{INTRODUCTION}

The work purpose is to study the heat transfer between an exhaust pipe of a car and thermoelectric modules. These modules were installed in the exhaust of the vehicle, as can be seen in Figures 1 and 2 .

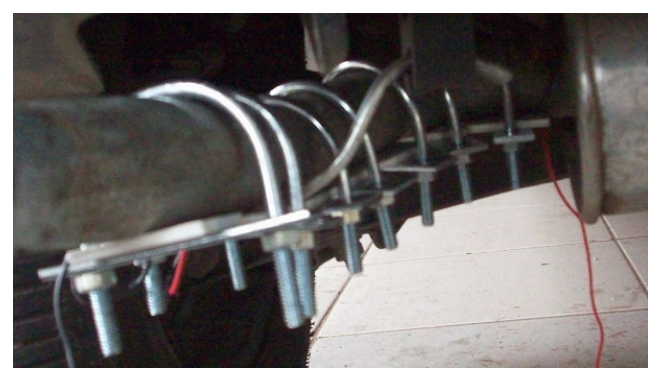

Figure 1. Thermoelectric modules near the exhaust.

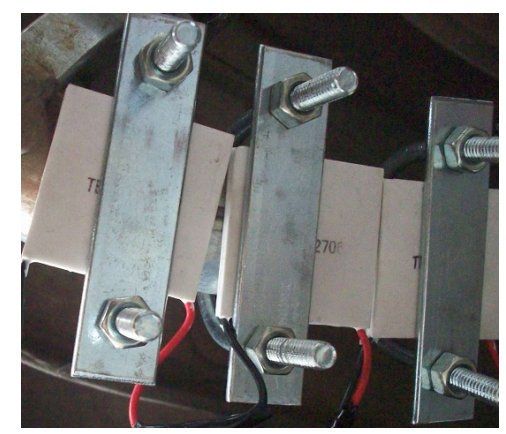

Figure 2. Thermoelectric modules installed near the exhaust. 


\section{HEAT TRASFER}

Heat transfer is the energy transport that occurs when quantities of matter that have different temperatures are placed in thermal contact. According to Moran et al. (2005), from the study of thermodynamics, it is learned that energy can be transferred through interactions that include the transfer of energy by heat and work, as well as the energy transfer associated with flow of pasta.

Heat transfer can occur in 3 different modes: conduction, convection and radiation.

\section{Conduction}

According to Moran et al. (2005), the conduction analysis concerns the determination of the temperature distribution in a medium resulting from the conditions at its borders. With the knowledge of the temperature distribution, the thermal flux distribution can be determined using the Fourier law. The one-dimensional Fourier law relates the thermal flux () in the $\mathrm{x}$-direction, the area $\left(\mathrm{m}^{2}\right)$, to the product of the thermal conductivity (W / m.K) by the temperature gradient $(\mathrm{dT} / \mathrm{dx})$, in the $\mathrm{x}$-direction.

$$
q_{s}^{\prime}=k A \frac{d T}{d x}
$$

Considering the way that the temperature distribution in medium resulting from conditions imposed at the boundaries can be determined, in the case of one-dimensional transient condition with volumetric generation of energy, the heat equation is:

$$
\frac{\partial}{\partial \mathrm{x}}\left(k \frac{\partial T}{\partial x}\right)+\dot{q}=\rho c \cdot \frac{\partial T}{\partial t}
$$

Where the temperature is a function of the $\mathrm{x}$ coordinate and time, $\mathrm{T}(\mathrm{x}, \mathrm{t})$. Conditions of permanent regime, with volumetric generation of energy:

$$
\frac{d}{d \mathrm{x}}\left(k \frac{d T}{d x}\right)+\dot{q}=0
$$

Conditions of permanent regime, without volumetric generation of energy, where the temperature, $\mathrm{T}(\mathrm{x})$, depends only on the $\mathrm{x}$-coordinate:

$$
\frac{d}{d \mathrm{x}}\left(k \frac{d T}{d x}\right)=0
$$

There is the appearance of the properties $\mathrm{p}, \mathrm{c}$ and $\mathrm{k}$ in the heat Equation (2). The pc product $\left(\mathrm{J} / \mathrm{m}^{3} \cdot \mathrm{K}\right)$ is called volumetric heat capacity and measures the capacity of a material to store energy in the form of heat. The thermal conductivity $(\mathrm{k})$ is a transport property that depends mainly on the material, since it is the coefficient of rate associated with the Fourier Law.

Conduction problems when the temperature distribution in a medium was determined solely by boundary conditions could be represented by thermal circuit resistances. There is an additional effect on the temperature distribution of processes that may be occurring inside the medium. In particular, these are the common geometries with a uniform volumetric rate of energy generation $\dot{\mathrm{q}}\left(\mathrm{W} / \mathrm{m}^{3}\right)$, which arises from the energy conversion processes. For this situation the medium can't be represented by a thermal circuit, but it is necessary to solve the heat equation to obtain the temperature distribution and, thus, the thermal flow.

All the phenomena that lead to the generation of internal energy can be modeled as occurring in distributed form and the total rate of internal generation is proportional to the volume. Thus, they are called volumetric phenomena. If the internal energy generation $\mathrm{E} \dot{\mathrm{g}}(\mathrm{W})$ occurs uniformly through a medium of volume $\mathrm{V}\left(\mathrm{m}^{3}\right)$, the volumetric generation rate $\dot{\mathrm{q}}\left(\mathrm{W} / \mathrm{m}^{3}\right)$ can be defined.

$$
\dot{q}=\frac{E \dot{g}}{V}
$$

In case of electric current flow through a resistor, the rate of internal energy generation, also known as electrical power dissipation, can be represented as:

$$
E \dot{g}=I^{2} * R
$$

Consider a flat wall in which there is uniform generation of energy per unit volume (constant) and the surfaces are kept at $\mathrm{T}_{\mathrm{s}, 1}$ and $\mathrm{T}_{\mathrm{s}, 2}$. For a constant thermal conductivity $\mathrm{k}$, the appropriate form of the heat equation is:

$$
\frac{d^{2} T}{d \mathrm{x}^{2}}+\frac{\dot{q}}{k}=0
$$

The general solution for the temperature distribution is:

$$
T=-\frac{\dot{q}}{2 k} x^{2}+C_{1} x+C_{2}
$$

By substitution, it can be verified that Equation (8) is a solution for the heat equation. For the boundary conditions we have: 


$$
T(0)=T_{S, 1} \quad T(L)=T_{S, 2}
$$

So the temperature distribution for the case of the asymmetric boundary conditions is:

$$
\begin{aligned}
T(x)=-\frac{\dot{q} L^{2}}{2 k}\left(1-\frac{x^{2}}{L}\right)+ & \\
& +\frac{T_{s, 2}-T_{s, 1}}{2} \cdot \frac{x}{L}+\frac{T_{s, 2}-T_{s, 1}}{2}
\end{aligned}
$$

\section{Convection}

According to Moran et al. (2005), the problem of convection is to determine the effects of surface geometry and runoff conditions on the resulting convection coefficient $(\mathrm{h})$ of the boundary layers that develop on the surface. The heat transferred by convection is given by:

$$
q_{\text {convc }}=h_{x} A\left(T_{s}-T_{\infty}\right)
$$

According to equation below, it is possible to find the total heat transferred by convection.

$$
\left.q=\bar{h} A_{x}-T_{\infty}\right)
$$

This coefficient is usually obtained through correlations that incorporate Reynolds, Nusselt and Prandtl. Parallel flow on a flat plate occurs in various engineering applications. The boundary layer flow conditions are characterized by the Reynolds number.

$$
\operatorname{Re}=\frac{V . L}{v}
$$

The Prandtl number is defined by equation below:

$$
\operatorname{Pr}=\frac{v}{\alpha}
$$

For laminar flow, the thicknesses of the hydrodynamic and thermal boundary layers depend on the number of Prandtl, dimensionless number representing the ratio of momentum and thermal diffusivity.

$$
\delta=5 \operatorname{Re}_{x}^{-1 / 2}
$$

$$
\operatorname{Re}_{L}=\frac{\mu_{\infty} . L}{v}
$$

$$
N u_{x}=\frac{h_{x} \cdot x}{k}=0.332 \operatorname{Re}_{x}^{1 / 2} \operatorname{Pr}^{1 / 3}
$$

The expression for mid convective heat transfer coefficient for a flat surface is given by:

$$
\overline{N u_{x}}=\frac{\overline{h_{x}} \cdot x}{k}=0.664 \mathrm{Re}_{x}^{1 / 2} \operatorname{Pr}^{1 / 3}
$$

For turbulent flow, the boundary layer development is strongly influenced by random velocity and less by molecular motion. Therefore, the relative growth of boundary layer does not depend on the number of Prandtl. That is, the thicknesses of the hydrodynamic and thermal boundary layers are approximately equal.

$$
\begin{gathered}
\delta=0.37 \mathrm{Re}_{x}^{-1 / 5} \\
N u_{x}=\frac{h_{x} \cdot x}{k}=0.0296 \operatorname{Re}_{x}^{4 / 5} \operatorname{Pr}^{1 / 3}
\end{gathered}
$$

\section{Radiation}

As Moran et al. (2005), all surfaces at a nonzero temperature emit energy in the form of electromagnetic waves. Therefore, in the absence of an intervening medium, there is heat transfer by radiation between two surfaces having different temperatures.

$$
\mathrm{q}=\varepsilon \sigma A\left(T s^{4}-\mathrm{Tviz}^{4}\right)
$$

\section{THERMOELECTRIC}

According to Hargreaves, Vasconcellos and Barros (2013), thermoelectric power plants are associated with thermal and electrical phenomena, since they can convert thermal energy to electric energy and vice versa. In general, thermoelectric modules have two modes of operation: electric power generation and cooling. Generators take advantage of the rejected heat from certain sources to create a temperature gradient needed to generate a continuous voltage. The refrigerators use an electrical potential difference applied at the junctions to create the temperature gradient between the plates. Basically, since the discovery of thermoelectric effects in the early nineteenth century, there has been little development in terms of improving its efficiency. 


\section{PELTIER CELLS}

Peltier Cells, also known as thermoelectric plates, are small units that use condensed matter technology to operate for the purpose of transferring heat from a cold source to a hot source. A typical unit has a thickness of a few millimeters and a square shape $(4 \times 40 \times 40 \mathrm{~mm})$. These modules are the union of ceramic plates with small cubes of Bi2Te3 (bismuth telluride) between the ceramic plates. This series of elements is welded between the two ceramic plates, electrically in series and thermally in parallel. When a DC current passes through one or more pairs of ntype and p-type elements, there is a reduction in joint temperature (cold side) resulting in an absorption of heat from the environment. This heat is transferred by the electron transport pellet and emitted on the other side (hot side) via electrons moving from a high state to a low state, as shown in Figure 3 (it can be found on the website: http://www.peltier.com.br. Access at 08/15/2016). A typical Peltier cell operates according to Peltier-Seebeck effect. The effects are described below.

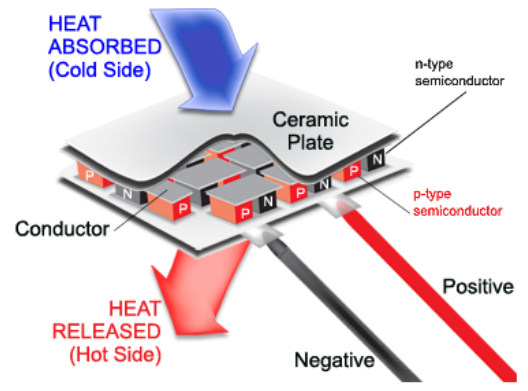

Figure 3. Schematic of a Peltier Cell.

The thermal conductivity of a thermoelectric module can be calculated using equation below:

$$
k=\frac{K \cdot A}{L}
$$

\section{FIGURE OF MERIT}

The figure of merit is a mathematical function that represents the performance of the equipment. In the case of thermoelectric, it is given for each material and expressed by $1 / \mathrm{K}$, and can be expressed:

$$
Z=\frac{\alpha^{2}}{\rho k}
$$

\section{Conversion Efficiency of Peltier Plates}

According to Thermoelectrics (2008), it can be demonstrated that the maximum efficiency of a thermoelectric material depends on two terms. The first is the efficiency of Carnot, in which all thermal machines can not exceed this efficiency. The second is a term that depends on the thermoelectric properties, Seebeck coefficient, electrical resistivity and thermal conductivity, which together form the property of the material we call Z, the figure of Merit.

$$
n_{\max }=1-\frac{T c}{T H} \cdot \frac{\sqrt{1+Z}-1}{\sqrt{1+Z}+1}
$$

\section{METHODS}

This is a part of the work that temperature measurements along the exhaust will show and also the calculations involving heat transfer between the car exhaust and the thermoelectric modules.

With the aid of a Minipa laser thermometer, the temperature of the exhaust was measured, as shown in Figure 4 and Table 1. Ambient temperature $\left(25^{\circ} \mathrm{C}\right)$

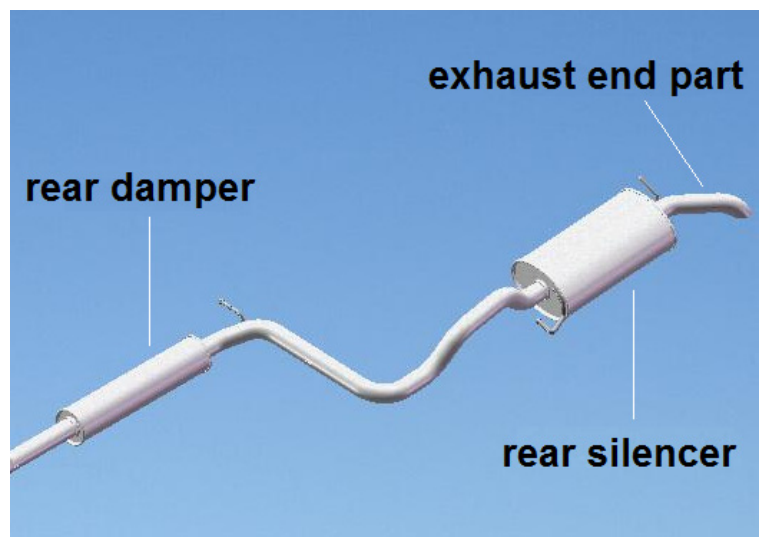

Figure 4. Vehicle exhaust.

Table 1. Temperatures along the vehicle exhaust.

\begin{tabular}{|c|c|c|c|}
\hline & Morning & Afternoon & Night \\
\hline Rear & $150^{\circ} \mathrm{C} \sim$ & $160^{\circ} \mathrm{C} \sim$ & $140^{\circ} \mathrm{C} \sim$ \\
Damper & $180^{\circ} \mathrm{C}$ & $175^{\circ} \mathrm{C}$ & $160^{\circ} \mathrm{C}$ \\
\hline Rear & $120^{\circ} \mathrm{C} \sim$ & $140^{\circ} \mathrm{C} \sim$ & $120^{\circ} \mathrm{C} \sim$ \\
Silencer & $140^{\circ} \mathrm{C}$ & $160^{\circ} \mathrm{C}$ & $135^{\circ} \mathrm{C}$ \\
\hline Exhaust & $85^{\circ} \mathrm{C} \sim$ & $90^{\circ} \mathrm{C} \sim$ & $65^{\circ} \mathrm{C} \sim$ \\
End Part & $115^{\circ} \mathrm{C}$ & $130^{\circ} \mathrm{C}$ & $100^{\circ} \mathrm{C}$ \\
\hline
\end{tabular}

From some values provided by the manufacturer, it was possible to calculate the thermal conductivity value $\mathrm{k}(\mathrm{W} / \mathrm{m} . \mathrm{K})$, required for the thermal calculations, which are described below.

Seebeck voltage of thermoelectric module: $\mathrm{Sm}=\mathbf{0 . 0 5 0 7 7} \mathrm{V} / \mathrm{K}$.

Thermal condutance of the thermoelectric module

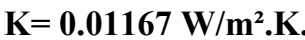

Figure of Merit of the thermoelectric module has the value of $2.5 \times 10^{-3} 1 / \mathrm{K}$.

According to the thermal conductance above 
and with equation 21 , it is possible to find the thermal conductivity of the thermoelectric module:

$$
\begin{aligned}
& \mathrm{K}=0.01167 \mathrm{~W} / \mathrm{m}^{2} . \mathrm{K} \\
& \mathrm{A}=0.0016 \mathrm{~m}^{2} \\
& \mathrm{~L}=0.04 \mathrm{~m} \\
& \mathrm{k}=4.668 \times 10^{-4} \mathrm{~W} / \mathrm{m} \cdot \mathrm{k}
\end{aligned}
$$

The decision was made to install the Peltier cells at the end of the exhaust, where the temperature is lower. The temperature difference was $59^{\circ} \mathrm{C}$. With the aid of a multimeter the voltage in the thermoelectric modulus was also measured and $1.9 \mathrm{~V}$ was obtained. Then according to the equation that is the definition of the Seebeck effect, it is possible to find the coefficient of Seebeck:

$$
\begin{aligned}
& \text { Voc }=1.9 \mathrm{~V} \\
& \Delta \mathrm{T}=59^{\circ} \mathrm{C} \\
& \alpha=0.0322 \mathrm{~V} / \mathrm{K}
\end{aligned}
$$

\section{RESULTS AND DISCUSSION}

After doing the experiments following the methods is the time to present calculations.

\section{Conduction}

According to the hot and cold temperatures found above, the value of $\mathrm{k}$ calculated above and with equation 9 it is possible to find the uniform volumetric rate of heat generation of the thermoelectric module, as shown in Figure 5:

$$
T(x)=-\frac{\dot{q} L^{2}}{2 k}\left(1-\frac{x^{2}}{L}\right)+\frac{T_{s, 2}-T_{s, 1}}{2} \cdot \frac{x}{L}+\frac{T_{s, 2}+T_{s, 1}}{2}
$$

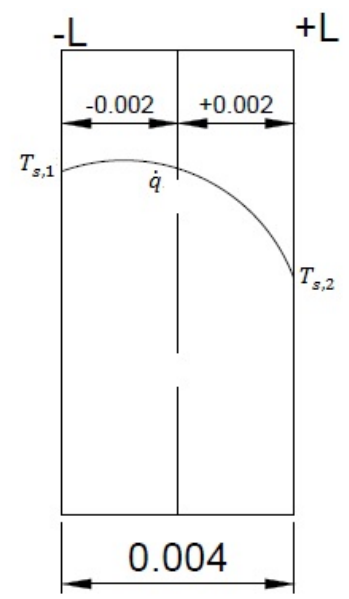

Figure 5. Conduction on a flat wall with uniform heat generation.

$\mathrm{k}=4.668 \times 10^{-4} \mathrm{~W} / \mathrm{m} . \mathrm{K}$

$\mathrm{T}_{\mathrm{s}, 1}=85^{\circ} \mathrm{C}-358 \mathrm{~K}$

$\mathrm{T}_{\mathrm{s}, 2}=26^{\circ} \mathrm{C}-299 \mathrm{~K}$

$\mathrm{L}=0.004 \mathrm{~m}$

$\mathrm{V}=$ volume de uma célula de Peltier $=6.4 \times 10^{-6} \mathrm{~m}^{3}$
Para $\mathrm{x}=-0.002 \mathrm{~m} \mathrm{e} \mathrm{T}(0)=358 \mathrm{~K}$ :

$$
\begin{aligned}
& 358=-\frac{\dot{q} \times 0.004^{2}}{2 \times 4.668 \times 10^{-4}}\left(1-\frac{-0.002^{2}}{0.004}\right)+ \\
& +\left(\frac{299-358}{2} \cdot \frac{-0.002}{0.004}\right)+\left(\frac{358-299}{2}\right)
\end{aligned}
$$

$\dot{\mathrm{q}}=25.6 \times 10^{3} \mathrm{~W} / \mathrm{m}^{3}$

$\mathrm{q}=25.6 \times 10^{3} .6 .4 \times 10^{-6}$

$q_{\text {cond }}=0.164 \mathrm{~W}$

\section{Convection}

According to Equation 15 and referring to Table TC-3 (Attachment A), one can find the local Reynolds number. Table data: $\mathrm{T}=300 \mathrm{~K}$ and $\mathrm{p}=1 \mathrm{~atm}$.

$$
\begin{aligned}
& \mu_{\infty}=10 \mathrm{~m} / \mathrm{s} \\
& \mathrm{L}=0.04 \mathrm{~m} \\
& v=15.89 \times 10^{-6} \mathrm{~m}^{2} / \mathrm{s} \\
& \operatorname{Re}_{L}=\frac{10 \times 0.04}{15.89 \times 10^{-6}} \\
& \operatorname{Re}_{\mathrm{L}}=0.25173 \times 10^{5}
\end{aligned}
$$

Since $\operatorname{Re}_{\mathrm{L}}<\mathrm{Re}_{\mathrm{x}, \mathrm{c}}=5 \times 10^{5}$, the flow is laminar over an entire plate. According to equation 17, and referring to Table TC-3 (Appendix A), the local Nussel number can be found. Table data: $T=300 \mathrm{~K}$ and $\mathrm{p}=1 \mathrm{~atm}$.

$$
\begin{aligned}
& \operatorname{Pr}=0.707 \\
& \operatorname{Re}_{\mathrm{L}}=0.25173 \times 10^{5} \\
& \overline{\mathrm{Nu}_{\mathrm{x}}}=0.664 \mathrm{Re}_{\mathrm{x}}^{1 / 2} \operatorname{Pr}^{1 / 3} \\
& \overline{\mathrm{Nu}_{\mathrm{x}}}=0.664 \cdot\left(0.25173 \times 10^{5}\right)^{1 / 2} \cdot(0.707)^{1 / 3} \\
& \overline{\mathrm{Nu}_{\mathrm{x}}}=93.846
\end{aligned}
$$

The mid coefficient of heat transfer by convection is also given by equation 17 :

$$
\begin{aligned}
& \overline{\mathrm{Nu}_{\mathrm{x}}}=93.846 \\
& \mathrm{k}=4.668 \times 10^{-4} \mathrm{~W} / \mathrm{m} \cdot \mathrm{K} \\
& \mathrm{x}=0.04 . \overline{h_{x} \cdot x} \\
& \overline{N u_{x}}=\frac{\overline{h_{x}} \cdot 0.04}{4.668 \times 10^{-4}} \\
& 93.846=-\frac{\mathrm{m}^{2} . \mathrm{K}}{\overline{\mathrm{h}_{\mathrm{x}}}}=1.095 \mathrm{~W} / \mathrm{m}^{2}
\end{aligned}
$$

According to equation 11, it was possible to find the cooling rate per unit width of the plate, shown in Figure 6: 


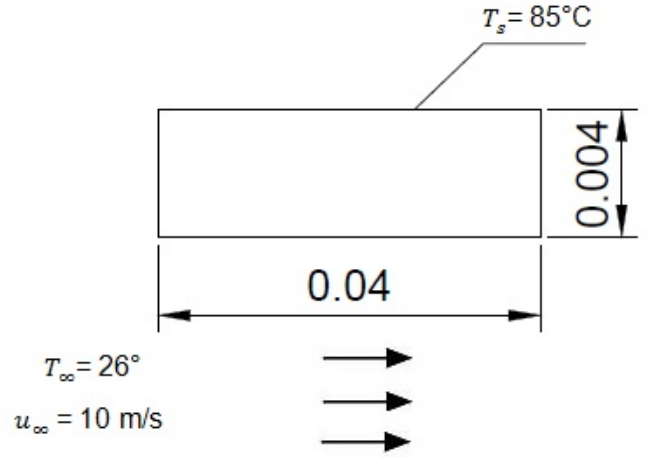

Figure 6. Air flow in the thermoelectric module.

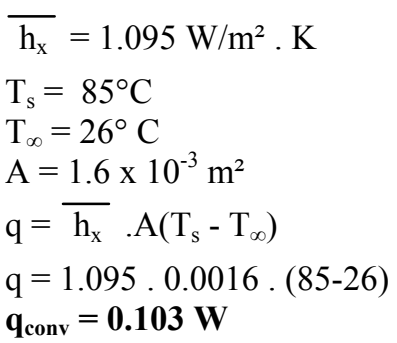

\section{Radiation}

According to equation 20 one can obtain the heat flux transferred by radiation.

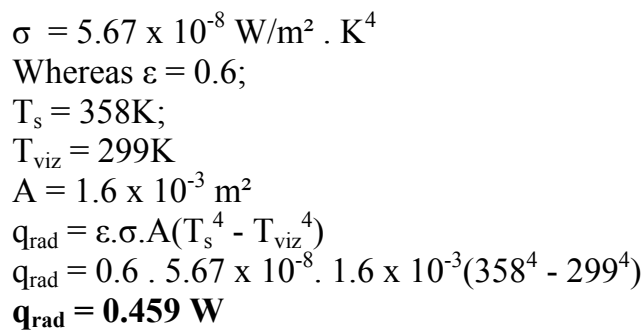

\section{CONCLUSIONS}

The work objective of studying the heat transfer between an automobile exhaust and thermoelectric modules has been fulfilled.

The decision to install the Peltier cells at the end of the exhaust, where the temperature is lower, was to avoid problems with high temperatures and because the temperature difference of $59^{\circ} \mathrm{C}$ was enough to perform the experiment.

The most interesting part of this article was the calculations of heat transfer, in 3 different modes: conduction, convection and radiation. The results for the heat transfer rates between the car exhaust and the thermoelectric modules were satisfactory. $0.164 \mathrm{~W}$ was obtained by convection $0.103 \mathrm{~W}$ and $0.459 \mathrm{~W}$ radiation.

An important observation was made is regarding the temperature difference. The larger the difference, the greater the values of the heat transfer rates would have been. So it's probably in the coldest regions of the country it's possible to get better results.

\section{ACKNOWLEDGEMENTS}

The author acknowledge with gratitude the support of the college Federal Center for Technology Education of Minas Gerais (CEFET-MG) in Brazil. And author likes to thank all the teachers involved at work.

\section{REFERENCES}

Hargreaves, B. O., Vasconcellos, G. L. F., Barros, and Lucas, T., 2013, Estudo de um Sistema de Refrigeração Auto Suficiente, Undergraduate Thesis, PUC-MG, Belo Horizonte, MG. (in Portuguese)

Moran, M. J., Shapiro, H. N., Munson, B. R., Dewitt, D. P, 2005, Introdução a Engenharia de Sistemas Térmicos, Editora LTC. (in Portuguese)

Thermoelectrics, 2008, The Science of Thermoelectric Materials, Caltech Materials Science, California Technological University's.

Seebeck, T. J., 1822, Magnetische Polarisation der Metalle und Erse Durch Temperature-Differenz, Abhandlungen der Deutxhen Akademieder Wissenschaften su Berlin. (in German)

\section{APPENDIX A}

Table TC-3. Thermo-physical properties of gases at atmospheric pressure.

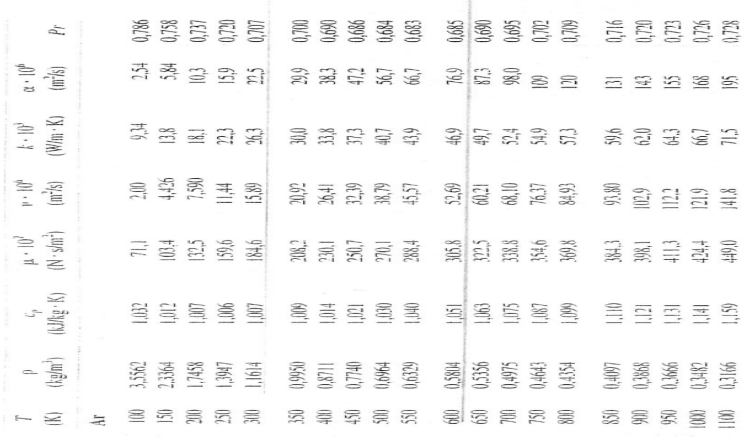

